\title{
LÍMITES A LA DOCENCIA EN LOS SERVIDORES Y FUNCIONARIOS PÚBLICOS
}

\author{
Limits to Teaching in Public Servant and Officials
}

\author{
Giovana Hurtado Magán \\ Universidad ESAN, Perú \\ https:/ / orcid.org/0000-0003-3556-1847
}

\section{Resumen}

La Constitución Política del Perú establece que los servidores públicos en general no pueden percibir doble remuneración o ingresos del Estado; además, con respecto a ciertos altos funcionarios, señala la incompatibilidad con el ejercicio de otras actividades públicas o privadas, facultando únicamente la función docente. La contratación de funcionarios como docentes en las instituciones de la Administración Pública se efectúa frecuentemente mediante los mecanismos que establece la Ley de Contrataciones del Estado; esta norma, sin embargo, señala diversas incompatibilidades para ser participante, postor o contratista en los procesos de selección. Mediante una metodología de análisis hermenéutico, se analizan las normas que establecen limitaciones y facultan el ejercicio docente de los servidores públicos en general, así como de los jueces, los fiscales, los congresistas, los miembros de la Junta Nacional de Justicia y del Jurado Nacional de Elecciones.

Palabras clave: contratación pública, impedimentos a funcionarios públicos, prohibiciones a funcionarios públicos, docencia, función pública

\begin{abstract}
The Political Constitution of Peru establishes that public servants in general cannot receive double remuneration or income from the State; furthermore, with respect to certain officials, it points out the incompatibility of the exer-
\end{abstract}


cise of other public or private activities, empowering only the exercise of the teaching function. The hiring of civil servants as teachers in Public Administration institutions is frequently carried out through the mechanisms that the State Contracting Law empowers; however, this norm indicates various incompatibilities to be a participant, bidder or contractor in the selection processes. Through a hermeneutical analysis methodology, we are going to analyze the norms that establish limitations and empower the teaching practice of public servants in general, as well as judges, prosecutors, congressmen, members of the National Board of Justice and the National Jury. of Elections.

Keywords: public contracting, impediments to public officials, prohibitions to public officials, teaching, public function.

\section{Introducción}

El legislador ha incorporado determinadas garantías para asegurar que los servidores públicos ejerzan sus funciones de manera neutral y ética. Con esta finalidad, propicia una burocracia profesional, y para lograrlo establece derechos, prohibiciones e incompatibilidades orientadas a evitar los conflictos de interés y preservar la imparcialidad de las decisiones que aquellos toman.

Los servidores públicos cumplen una serie de funciones, deberes y responsabilidades que desarrollan para satisfacer las necesidades permanentes de la administración pública ${ }^{1}$ y brindar servicios al ciudadano. Ejercen dichas tareas de conformidad con la finalidad pública para la cual han sido creadas por la administración a la que sirven. Existen, sin embargo, una serie de situaciones que definen si a los servidores públicos se les puede permitir realizar trabajos $\mathrm{u}$ oficios que sean compatibles con su función pública, sean de la misma naturaleza o no, o bien de naturaleza privada ${ }^{2}$.

Las disposiciones que prohibían recibir una doble remuneración del Estado se encuentran ya en el derecho español. Así, por ejemplo, el rey Felipe $\mathrm{V}$ decretó la prohibición de percibir goces públicos duplicados bajo cualquier

1 David Francisco Camargo Hernández, Funcionarios públicos: evolución y prospectiva (Eumed, s. f.), https:/ / www.eumed.net/libros-gratis/2005/dfch-fun/index.htm

2 Alberto Palomar Olmeda, Derecho de la función pública: régimen jurídico de los funcionarios públicos, 11. ${ }^{a}$ ed. (Madrid: Dykinson, 2016). 
denominación ${ }^{3}$. Mediante la Ley XVI del 12 de febrero de 1717, aplicable también al Virreinato del Perú, se estableció la prohibición de gozar de más de un sueldo proveniente de los fondos de la Real Hacienda. El sustento de esta norma fue que los secretarios y oficiales de secretaría se deberían ocupar del real servicio al Rey con mayor puntualidad y con menor gasto para el erario. Esta norma se hizo extensiva a los ministros, contadores, oficiales de secretaría y demás subalternos; establecía también que, si era necesario el ejercicio de alguna otra comisión, esta sería encomendada por el rey, pero en ningún caso tendría retribución, salvo que por esta nueva comisión se pague un sueldo mayor, en cuyo caso se abonaría la diferencia ${ }^{4}$.

En Latinoamérica, la Constitución brasileña de 1988 también prohíbe la acumulación de cargos y empleos públicos ${ }^{5}$. En el Perú, la Constitución establece para los funcionarios públicos una serie de limitaciones en el ejercicio de ciertas actividades y coloca como excepción la docencia. Así, el artículo 40 señala que ningún funcionario o servidor público puede desempeñar más de un empleo o cargo público remunerado, salvo uno más por función docente.

Las incompatibilidades en el caso de los servidores públicos se clasifican ${ }^{6}$ en aquellas referentes a la contratación de personal, el ejercicio de cualquier función pública o privada, la prestación de servicios en el sector privado, el ser participante, postor o contratista en procesos de selección de proveedores del Estado, entre otros tipos. En el presente artículo se analizarán las incompatibilidades para ser participante, postor o contratista en los procesos de selección que realizan las entidades del Estado para la contratación de docentes a la luz de las normas que autorizan el ejercicio de la labor docente.

Se parte de precisar que, en general, de acuerdo con la Constitución, todos los servidores pueden ejercer un solo cargo público adicional por función docente. En sus diversos artículos señala expresamente las limitaciones para el

3 Ángel Martín Díez-Quijada, «La remuneración de los funcionarios», Revista de Administración Pública 39 (1962): 172, http://www.cepc.gob.es/publicaciones/revistas/ revistaselectronicas? IDR $=1 \&$ IDN=39\&IDA $=22245$

4 Marcelo Martínez Alcubilla, Códigos antiguos de España. Colección completa de todos códigos de España, desde el Fuero Juzgo hasta la novísima recopilación (Madrid: Arco de Santa María, 1885): 2043.

5 F. Lins de Lessa Carvalho, «La función pública en el mundo: rasgos jurídicos, tendencias y retos de siete modelos comparados», Ars Iuris Salmanticensis 7, n. ${ }^{\circ} 1$ (2019), https:/ / revistas. usal.es/index.php/ais/article/view/21889

6 Janery Boyer Carrera, El derecho de la función pública y el servicio civil: nociones fundamentales (Lima: Pontificia Universidad Católica del Perú, 2019), 124,125. 
ejercicio profesional con excepción de la docencia que tienen, por ejemplo, los jueces, los fiscales, los miembros de la Junta Nacional de Justicia y del Jurado Nacional de Elecciones, así como los congresistas.

A continuación, se analizan las normas sobre el ejercicio docente para estos funcionarios.

\section{Metodología}

Mediante el análisis hermenéutico de la Constitución Política del Perú, la Ley de Contrataciones del Estado (Ley 30225) y la Ley Marco del Empleo Público (Ley 28175), se plantearán interrogantes sobre la interpretación de los impedimentos para la docencia a la luz del Acuerdo de Sala Plena 003-2021/TCE del Tribunal de Contrataciones del Estado, que modificó el Acuerdo 008-2020/ TCE con respecto al alcance de los impedimentos establecidos en diversos literales del numeral 11.1 del artículo 11 de la Ley 30225 para el ejercicio de la docencia. Además, se estudiarán las normas especiales que establecen limitaciones a los jueces, los fiscales, los miembros de la Junta Nacional de Justicia y del Jurado Nacional de Elecciones, así como a los congresistas.

\section{Marco legal sobre el ejercicio de la docencia por los servidores públicos}

De acuerdo con la Constitución Política del Perú, los funcionarios o servidores públicos solo pueden ejercer un cargo o un empleo público como docentes en instituciones educativas públicas ${ }^{7}$. Se considera como tales a las universidades, institutos, escuelas, academias, colegios, etc. Además, se entiende que los

7 Artículo 40.- La ley regula el ingreso a la carrera administrativa, y los derechos, deberes y responsabilidades de los servidores públicos. No están comprendidos en dicha carrera los funcionarios que desempeñan cargos políticos o de confianza. Ningún funcionario o servidor público puede desempeñar más de un empleo o cargo público remunerado, con excepción de uno más por función docente.

No están comprendidos en la función pública los trabajadores de las empresas del Estado o de sociedades de economía mixta.

Es obligatoria la publicación periódica en el diario oficial de los ingresos que, por todo concepto, perciben los altos funcionarios, y otros servidores públicos que señala la ley, en razón de sus cargos. 
funcionarios o servidores públicos en general sí pueden ser docentes en instituciones educativas privadas (universidad, instituto, escuela, colegio, etc.).

El artículo 3 de la Ley Marco del Empleo Público, Ley 28175, establece la prohibición de percibir más de un ingreso por parte del Estado, es así como los servidores públicos están impedidos de percibir del Estado más de una remuneración, retribución, emolumento o cualquier tipo de ingreso.

Se incluye dentro de esta prohibición la percepción de remuneración y pensión por servicios prestados al Estado. Las únicas excepciones a la prohibición de doble percepción son la función docente y la percepción de dietas por participar en el directorio de alguna entidad o empresa pública.

Esta prohibición se encuentra consagrada también en el artículo 38 de la Ley de Servicio Civil, Ley 30057, que contempla como únicas excepciones la percepción de ingresos por función docente efectiva y el cobro de dietas por la participación en el directorio de alguna entidad o empresa estatal, en tribunales administrativos o en otros órganos colegiados.

El artículo 152 del Reglamento de la Ley de Servicio Civil, aprobado por Decreto Supremo 040-2014-PCM, afirma que el servidor tiene derecho a gozar de hasta seis horas semanales de permiso por docencia. Según esta norma, la docencia no se ejerce únicamente en universidades, sino también como parte de actividades de formación profesional o laboral en cualquier entidad pública. El requisito es que esas horas sean compensadas.

Respecto al presente análisis, las normas sobre servicio civil precisan que la labor de docencia puede desarrollarse dentro o fuera del horario de trabajo; en el primer caso, debe ser compensada. Un servidor público se puede desempeñar como docente en una universidad pública o privada, en una institución educativa de cualquier nivel educativo pública o privada o en una entidad del Estado dedicada a la formación profesional o laboral. El único requisito es que la docencia sea efectiva.

De acuerdo con el artículo 80 de la Ley Universitaria, Ley 30220, los docentes pueden ser de tres clases: ordinarios, extraordinarios o contratados. Los docentes ordinarios comprenden, a su vez, tres categorías: principales, asociados y auxiliares. Los docentes extraordinarios se clasifican en eméritos, honorarios o sus equivalentes. Los contratados, por su parte, no ostentan ninguna categoría y prestan servicios a plazo determinado en los diversos niveles de enseñanza y bajo las condiciones establecidas contractualmente. 
Cuadro 1: Clases y categorías de docentes

\begin{tabular}{|l|l|}
\hline Clases de docentes \\
\hline Ordinario & $\begin{array}{l}\text { Categorías: } \\
\text { Principal } \\
\text { Asociado } \\
\text { Auxiliar }\end{array}$ \\
\hline Extraordinario & $\begin{array}{l}\text { Emérito } \\
\text { Honorario }\end{array}$ \\
\hline Contratado & \\
\hline
\end{tabular}

Elaboración propia.

El artículo 85 de la Ley Universitaria establece los regímenes de dedicación de los profesores ordinarios: a dedicación exclusiva, a tiempo completo o a tiempo parcial. En el caso de los primeros, no tienen otra actividad remunerada que el ejercicio de la docencia en la universidad donde prestan sus servicios. Con respecto a los docentes a tiempo completo, su permanencia en la universidad es de cuarenta horas semanales en el horario que esta le señala. Finalmente, los docentes a tiempo parcial suman un número de horas semanales inferior a cuarenta.

Por otra parte, el artículo 88.8 otorga a los docentes el derecho a gozar de licencia voluntaria en el caso de que asuman un mandato legislativo, municipal o regional. Si un profesor es nombrado ministro o viceministro de Estado, o presidente de una región, la licencia es forzosa. En ambas situaciones, conserva su categoría y clase docente.

Concordando las normas del servicio civil con la Ley Universitaria, los funcionarios públicos podrán ser igualmente docentes ordinarios y extraordinarios - en cualquiera de sus categorías - o contratados. Dada esta situación, solo podrían ejercer la docencia a tiempo parcial en una o más universidades públicas o privadas. La carga lectiva no debe superar las seis horas semanales si estas se desarrollan dentro del horario de trabajo de la entidad en la que laboran.

Entonces, según estas disposiciones, los servidores públicos sí pueden dedicarse a la docencia universitaria fuera del horario de trabajo, pero por la cantidad de horas que les sean factibles dictar tanto en universidades públicas como privadas. Nunca podrán, sin embargo, hacerlo de manera exclusiva y a tiempo completo. 


\section{La contratación de docentes en las administraciones públicas peruanas}

Como se puede apreciar, el ejercicio de la función docente no se limita a las universidades, puesto que diversas instituciones públicas, con la finalidad de capacitar y promover el desarrollo de sus recursos humanos, o bien para extender los conocimientos necesarios para el ejercicio de sus funciones, contratan a servidores públicos para que se desempeñen como profesores de sus centros de capacitación. Ejemplos de ello son la Academia de la Magistratura, la Escuela Nacional de Control, la Escuela Nacional de Administración Pública, la Escuela Nacional del Indecopi, la Academia de Fiscalización Ambiental o el Centro de Estudios Constitucionales.

En estos casos, el mecanismo de contratación más efectivo es la emisión de una orden de servicio. Generalmente, los montos para estas contrataciones no superan las ocho UIT, por lo que, de acuerdo con el artículo 5.1.a) del Texto Único Ordenado de la Ley 30225, Ley de Contrataciones del Estado, constituye un supuesto excluido de la aplicación de dicha norma.

De cara al perfil de los profesionales cuyos impedimentos se analizan en el presente estudio, el artículo 11.1 del TUO de la Ley de Contrataciones del Estado señala que se encuentran impedidos de ser participantes, postores, contratistas o subcontratistas -incluso en las mencionadas contrataciones por montos inferiores a 8 UIT- los siguientes funcionarios:

a) los congresistas de la República;

b) los jueces supremos de la Corte Suprema de Justicia de la República;

c) los titulares y los miembros del Jurado Nacional de Elecciones;

d) los titulares y los miembros de la Junta Nacional de Justicia;

e) Los jueces de las Cortes Superiores de Justicia, pero solo en el ámbito de su competencia territorial;

f) Los titulares de instituciones o de organismos públicos del Poder Ejecutivo en la entidad a la que pertenecen;

g) los funcionarios públicos en la entidad a la que pertenecen;

h) los empleados de confianza en la entidad a la que pertenecen;

i) los servidores públicos con poder de dirección o decisión en la entidad a la que pertenecen;

j) los gerentes de las empresas del Estado en la entidad a la que pertenecen;

k) y los servidores públicos, en general, en la entidad a la que pertenecen.

Estos impedimentos se aplican en cualquier proceso de contratación durante el tiempo que dure el ejercicio del cargo y hasta doce meses después de 
haber concluido este. Para los servidores públicos, en general, el impedimento posterior al fin de su servicio no es aplicable si careció de influencia, poder de decisión o información privilegiada sobre el proceso de selección.

El 16 de octubre de 2020 se publicó en el diario oficial El Peruano el Acuerdo de Sala Plena 008-2020/TCE del Tribunal de Contrataciones del Estado, que analizó los impedimentos establecidos en el precitado numeral 11.1 del TUO de la Ley de Contrataciones del Estado. Dicho tribunal precisó al respecto que los impedimentos son de carácter absoluto y se aplican a los contratos de locación de servicios que se perfeccionan mediante la recepción de las órdenes de servicios, en este caso para prestar servicios de enseñanza, o bien de dictado de clases o cursos en universidades públicas u entidades que imparten enseñanza como parte de sus funciones.

Sustenta el tribunal que, para garantizar el adecuado y eficiente uso de los fondos estatales y de las finalidades públicas, se deben observar los principios siguientes, establecidos por el artículo 2 del TUO de la Ley de Contrataciones del Estado: a) principio de libertad de concurrencia, b) principio de transparencia, c) principio de eficacia y eficiencia, y d) principio de competencia. Además, señala los principios que la Constitución sugiere como esenciales para llevar a cabo una contratación pública: moralidad, integridad, competencia efectiva, libre concurrencia, eficacia, eficiencia, transparencia.

Es oportuno precisar que la finalidad fundamental de los principios contenidos en la normativa sobre contrataciones del Estado es garantizar procesos transparentes y no discriminatorios, de manera que todos los operadores económicos se beneficien de la contratación pública mediante la libre circulación de mercancías y la libre prestación de servicios ${ }^{8}$. En el Perú, el consumo y la inversión pública constituyen una importante fuente de ingresos y han representado en los últimos cinco años el $16.5 \%$ del producto bruto interno 9 . Por esta razón, la contratación pública debe propiciar el funcionamiento transparente y libre del mercado, fomentar la utilización eficiente de los fondos públicos y garantizar el cumplimiento de las finalidades públicas ${ }^{10}$.

8 Miguel Ángel González Iglesias, En busca de la regeneración, renovación o mejora del comportamiento en la contratación pública: transparencia, lucha contra la corrupción, prohibiciones de contratar. La buena conducta empresarial (España: Universidad de Salamanca, 2020), 1-51.

9 Banco Central de Reserva del Perú, «Producto bruto interno por tipo de gasto (como porcentaje del PBI nominal), gráfico 95», Nota semanal 13 (8 de abril de 2021), https:/ / www.bcrp.gob.pe/ estadisticas/cuadros-de-la-nota-semanal.html (consultado el 12 de abril de 2021).

10 Antonio Fortes Martín, «La nueva fisonomía del derecho administrativo en materia de con- 
Retomando lo señalado por el Acuerdo 008-2020/TCE, las contrataciones deben satisfacer el interés público mediante la selección de proveedores en las mejores condiciones de calidad, precio y oportunidad. Con esto se busca evitar situaciones de privilegios, ventajas y direccionamientos indebidos a ciertos proveedores, así como conflictos de intereses que puedan producirse en autoridades que, a su vez, puedan tener la condición de proveedores del Estado.

Finalmente, se afirma que la naturaleza de la actividad docente no requiere necesariamente la utilización de los mecanismos contractuales previstos o supervisados por la Ley de Contrataciones del Estado y sus normas complementarias, sino que aquella se ejerce a través de otros contratos de naturaleza laboral, como los contratos administrativos de servicios (CAS). En atención a ello, se estableció que la docencia en el Estado desarrollada por los funcionarios públicos señalados en el numeral 11.1 del artículo 11 de la Ley de Contrataciones del Estado constituye una infracción tipificada en el literal c) del numeral 50.1 del artículo 50 de la referida ley.

Esta decisión afectó a varias universidades públicas, así como a las escuelas y academias de la administración pública peruana. Por esta razón, el 7 de abril de 2021, el Tribunal de Contrataciones del Estado tuvo que rectificarse adoptando el Acuerdo de Sala Plena 003-2021/TCE del Tribunal de Contrataciones del Estado que modifica el Acuerdo 008-2020/TCE. De esta manera, se dejó sin efecto el criterio interpretativo plasmado en sus numerales 1 y 2 , por los cuales se impedía la contratación como docentes de funcionarios o servidores públicos a través de los mecanismos establecidos en la Ley de Contrataciones. El nuevo acuerdo reinterpreta el alcance de estos impedimentos y establece que no se extienden a la labor docente cuando esta se ejerce bajo un régimen laboral como el de locación de servicios.

El alcance de esta interpretación nos pone en alerta, ya que el tribunal afirma que el contrato de locación de servicios de docencia tiene naturaleza laboral. Y esto deja abierta la posibilidad de reconocer que, a través de este mecanismo de contratación, existen derechos laborales. La pregunta que surge - pero que queda en el tintero porque no corresponde a este análisis- es: ¿cuál sería el régimen laboral de estos docentes y qué derechos tendrían?

tratación pública», Revista Digital de Derecho Administrativo 25 (2021), 11-53, https:/ / revistas. uexternado.edu.co/index.php/Deradm/article/view/6901/9469 
De otro lado, el tribunal reconoce la existencia de ciertos contratos en los cuales confluyen los siguientes supuestos: a) el contratante es una entidad que realiza función educativa; b) el contrato tiene por objeto el ejercicio de la labor docente; c) el docente contratado es un funcionario o servidor público con habilitación constitucional y legal para realizar dicha labor.

Con respecto a la afirmación hecha en el Acuerdo 008-2020/TCE referente al propósito de evitar situaciones de injerencia o ventaja por parte de los funcionarios o servidores públicos en las contrataciones del Estado que puedan distorsionar la competencia, el tribunal se corrige con el nuevo acuerdo. Manifiesta ahora que dichas situaciones carecen de respaldo, porque el ejercicio de la labor docente se otorga mediante habilitación constitucional y responde a otro orden de consideraciones; destaca, a su vez, que resulta conveniente para el Estado aprovechar las capacidades públicas y dotar de buenos docentes al sistema educativo.

Es importante recordar que las normas sobre incompatibilidad de actividades de los funcionarios públicos se fundamentan en la posibilidad de comprometer su imparcialidad, así como también en la necesidad de evitar el tráfico de influencias ${ }^{11}$. Esta situación, sin embargo, no se presenta en la actividad docente. Sin perjuicio de ello, la administración ostenta facultades de supervisión y sanción a los funcionarios que incumplan con estas normas.

Para tener una mejor comprensión sobre la docencia como excepción a la prohibición de doble percepción, es necesario estudiar las normas especiales que regulan las funciones de los cargos de congresista, juez, fiscal, miembro de la Junta Nacional de Justicia y del Jurado Nacional de Elecciones e interpretarlas contrastándolas con el análisis que hace en sus acuerdos el Tribunal de Contrataciones. Sobre esta base se establecerán algunas conclusiones.

\subsection{Función congresal}

El artículo 92 de la Constitución Política del Perú establece que la función de congresista es de tiempo completo; le está prohibido desempeñar cualquier otro cargo o ejercer profesión u oficio durante las horas de funcionamiento del Congreso. Además, el mandato de congresista es incompatible con el ejercicio

11 Alberto Palomar Olmeda, Derecho de la función pública: régimen jurídico de los funcionarios públicos (11. a ed.) (Madrid: Dykinson, 2016). 
de cualquier otra función pública, excepto la de ministro de Estado, y el desempeño - previa autorización del Congreso- de comisiones extraordinarias de carácter internacional. Además, existe una incompatibilidad con el ejercicio de los cargos de gerente, apoderado, representante, mandatario, abogado, accionista mayoritario o miembro del directorio de una empresa que tenga contratos de obra o de suministro con el Estado, administre rentas públicas, preste servicios públicos o haya recibido alguna concesión estatal.

La Carta Magna no especifica si los congresistas pueden ser docentes de instituciones educativas públicas o privadas (universidad, instituto, escuela, colegio, etc.). Así, al no haber prohibición expresa, se entiende que sí pueden ejercer la docencia fuera del horario de funcionamiento del Congreso.

El Reglamento del Congreso - modificada mediante Resolución Legislativa 013-2020-2021-CR (vigente desde el 10 de marzo de 2021) — determina la exclusividad de la función congresal. En el artículo 19 señala que el cargo de congresista es incompatible con:

a) El ejercicio de cualquier otra función pública, excepto la de ministro de Estado, y el desempeño, previa autorización del Congreso, de comisiones extraordinarias de carácter internacional.

b) La condición de gerente, apoderado, representante, mandatario, abogado, accionista mayoritario o miembro del directorio de empresas que tienen con el Estado contratos de obras, de suministro o de aprovisionamiento, o que administran rentas o prestan servicios públicos.

c) La condición de gerente, apoderado, representante, mandatario, abogado, accionista mayoritario o miembro del directorio de empresas o de instituciones privadas que durante su mandato parlamentario obtengan concesiones del Estado, así como de empresas del sistema bancario, financiero y de seguros supervisadas por la Superintendencia de Banca, Seguros y AFP.

Estas incompatibilidades son las mismas que establece el artículo 92 de la Constitución.

En cuanto a las prohibiciones que dispone el artículo 20 del Reglamento del Congreso figuran las de:

a) Desempeñar cualquier cargo o ejercer cualquier profesión u oficio durante las horas de funcionamiento del Congreso. 
b) Adquirir acciones o aceptar cargos o representaciones en empresas que tienen con el Estado contratos de obras, de suministro o de aprovisionamiento, o que administran rentas o prestan servicios públicos.

Según el análisis hecho por el Tribunal de Contrataciones del Estado, y plasmado en el segundo párrafo del numeral 1) del Análisis del Acuerdo de Sala Plena 003-2021/TCE, los congresistas no pueden ejercer la docencia en universidades públicas.

Surge en este punto una discrepancia con la posición asumida por el Tribunal, ya que las normas que establecen limitaciones deben ser expresas; por lo tanto, de acuerdo con el Reglamento del Congreso, los congresistas sí pueden desempeñarse como docentes en instituciones educativas públicas o privadas (universidad, instituto, escuela, academia, colegio, etc.) siempre que esta actividad sea ejercida fuera del horario de funcionamiento del Congreso.

El problema se podría presentar si el congresista ocupa un cargo de gerente, apoderado, representante, mandatario, abogado, accionista mayoritario o miembro del directorio de una institución educativa privada que, operando como empresa, haya celebrado algún contrato de obra o de suministro con el Estado, administre rentas públicas, preste servicios públicos o haya recibido alguna concesión de este. Todas estas situaciones, sin embargo, son poco frecuentes en la realidad contractual peruana.

\subsection{Función jurisdiccional y fiscal}

El artículo 146 de la Constitución Política del Perú establece la exclusividad de la función jurisdiccional al afirmar que esta es incompatible con cualquier otra actividad pública o privada, con excepción de la docencia universitaria fuera del horario de trabajo. De igual forma, el artículo 158 de la Carta Magna establece que los miembros del Ministerio Público tienen los mismos derechos y prerrogativas, con iguales obligaciones e incompatibilidades que los del Poder Judicial en la categoría respectiva.

Por tanto, según la Constitución, los jueces y, por extensión, los fiscales, solo pueden ser docentes de universidades públicas o privadas fuera del horario de trabajo.

Es oportuno mencionar que la Ley de Carrera Judicial, Ley 29277, reconoce como requisito especial para el cargo de magistrado, en sus diversos niveles, la docencia universitaria (artículos 6.2, 7.2, 8.2 y 9.2). Además, el numeral 13) del artículo 34 establece, en concordancia con lo establecido en la 
Constitución, que es deber de los jueces dedicarse exclusivamente a la función jurisdiccional. Autoriza, sin embargo, el ejercicio de la docencia universitaria, aunque únicamente en materia jurídica. Por otra parte, la norma permite la docencia como profesor a tiempo parcial, profesor investigador o conferencista, expositor, panelista o similar hasta por ocho horas semanales. Tales actividades docentes deben ser desarrolladas fuera del horario de despacho judicial. Conviene resaltar que la docencia universitaria en una determinada área del derecho es requisito para que los jueces accedan a una especialidad (artículo 38).

De otro lado, se prohíbe a los jueces aceptar cargos remunerados en instituciones públicas o privadas, a excepción de la docencia universitaria en materias jurídicas.

Según el análisis efectuado por el Tribunal de Contrataciones del Estado, plasmado en el tercer párrafo del numeral 1) del Acuerdo de Sala Plena 0032021/TCE, los jueces solo pueden ejercer la docencia universitaria a tiempo parcial, hasta por ocho horas semanales de dictado de clases y en horas distintas de las que corresponden al despacho judicial. Igualmente, con las mismas limitaciones, pueden realizar labores de investigación e intervenir, a título personal, en congresos y conferencias.

Según el análisis del Tribunal de Contrataciones del Estado plasmado en el sexto párrafo del numeral 1) del Acuerdo de Sala Plena 003-2021/TCE, los fiscales solo pueden ejercer la docencia universitaria. No se explaya sobre las características que debe reunir dicha práctica docente.

En consecuencia, los jueces y los fiscales solamente pueden ocupar un cargo remunerado como docentes universitarios a tiempo parcial, fuera del horario de despacho, con una carga lectiva máxima de ocho horas semanales, como profesores ordinarios en las categorías de profesor principal, asociado o auxiliar, o profesor extraordinario o contratado, y siempre que el curso verse sobre materia jurídica. Por tanto, no se permite el desempeño remunerado en una universidad como decano, director, jefe o coordinador de facultad, departamento o instituto. Lo contrario constituiría una falta muy grave (artículo 48.1).

\subsection{Miembros de la Junta Nacional de Justicia}

El artículo 156 de la Constitución Política del Perú establece que los miembros de la Junta Nacional de Justicia no deben incurrir en conflicto de intereses, por 
lo que el ejercicio de su función es incompatible con cualquier otra actividad pública o privada fuera del horario de trabajo, salvo la docencia universitaria. En consecuencia, solamente pueden ser docentes de universidades públicas o privadas fuera del horario de trabajo.

La Ley Orgánica de la Junta Nacional de Justicia, Ley 30916 establece en sus artículos $12^{12}$ y $66^{13}$ la exclusividad de la función de miembro de la junta, prohibiendo el desempeño de otros cargos públicos o privados, así como el ejercicio de profesión u oficio, salvo la docencia universitaria a tiempo parcial, siempre y cuando se desarrolle fuera del horario de funcionamiento de la Junta Nacional de Justicia y no afecte su normal desempeño. Además, el artículo $67^{14}$ prohíbe a los miembros el patrocinio de cursos de capacitación o preparación para aspirantes o postulantes en los procedimientos de designación que están a cargo de la junta; tampoco se les permite promover, pertenecer o patrocinar instituciones de este tipo, salvo la docencia universitaria.

Según el análisis efectuado por el Tribunal de Contrataciones del Estado, plasmado en el noveno párrafo del numeral 1) del Acuerdo de Sala Plena 0032021/TCE, los miembros de la Junta Nacional de Justicia solo pueden ejercer la docencia universitaria a tiempo parcial, y siempre que no afecte el normal funcionamiento de dicho organismo. No se analizan con más profundidad las características que debe tener el ejercicio de dicha labor docente.

En conclusión, los miembros de la Junta Nacional de Justicia solo pueden desempeñarse como docentes universitarios a tiempo parcial fuera del horario de funcionamiento de la Junta Nacional de Justicia, y siempre que no se

12 Artículo 12. Exclusividad de la función de miembro de la Junta Nacional de Justicia

La función de miembro de la Junta Nacional de Justicia es a tiempo completo. Está prohibido desempeñar cualquier otro cargo público o privado o ejercer cualquier profesión u oficio, a excepción de la docencia universitaria a tiempo parcial, y siempre y cuando no afecte el normal funcionamiento de la Junta Nacional de Justicia.

13 Artículo 66. Prohibición de desempeñar otros cargos

Los miembros de la Junta Nacional de Justicia se encuentran prohibidos de desempeñar cualquier otro cargo público o privado o ejercer cualquier profesión u oficio, a excepción de la docencia universitaria a tiempo parcial, fuera del horario de funcionamiento de la Junta Nacional de Justicia.

14 Artículo 67. Prohibición de patrocinar cursos

Los miembros de la Junta Nacional de Justicia están prohibidos de patrocinar, directa o indirectamente, ningún curso de capacitación o preparación para aspirantes o postulantes en los procedimientos a cargo de la Junta, ni promover, pertenecer o patrocinar instituciones de este tipo, salvo la docencia universitaria. 
trate de cursos de capacitación o preparación de aspirantes que no sean desarrollados por una universidad.

En realidad, el último párrafo del artículo 67 no está redactado de forma clara, pues no precisa qué significan: a) la excepción de la docencia universitaria en el patrocinio de cursos de capacitación o preparación de aspirantes o postulantes; y b) la excepción de la docencia en la promoción, pertenencia o patrocinio de instituciones que organizan cursos de capacitación o preparación de aspirantes o postulantes. Por ejemplo, si una universidad organiza un curso de preparación para el examen de selección a los cargos de jueces o fiscales, un miembro de la junta, en su condición de profesor universitario de esa casa de estudios, ¿podría ser docente en dicho curso? Entendemos que no, puesto que justamente lo que se busca es garantizar la imparcialidad de los integrantes de la junta y evitar que exista algún tipo de beneficio o preferencia por los egresados de este tipo de cursos que provienen de determinada universidad.

\subsection{Miembros del Jurado Nacional de Elecciones}

El artículo 180 de la Constitución Política del Perú establece que el ejercicio del cargo de miembro del Pleno del Jurado Nacional de Elecciones (JNE) es incompatible con cualquier otra función pública, excepto la docencia a tiempo parcial. Los miembros del JNE solo pueden desempeñarse como docentes a tiempo parcial en instituciones educativas públicas (universidad, instituto, escuela, academia, colegio, etc.); sí pueden serlo a tiempo completo (si este les alcanza) o a tiempo parcial en instituciones educativas privadas (universidad, instituto, escuela, colegio, etc.).

El artículo 15 de la Ley Orgánica del Jurado Nacional de Elecciones, Ley 30998, dispone que el ejercicio del cargo de miembro del Pleno del Jurado Nacional de Elecciones es incompatible con cualquier otra función pública, excepto la docencia a tiempo parcial.

El análisis del Tribunal de Contrataciones del Estado, plasmado en el décimo párrafo del numeral 1) del Acuerdo de Sala Plena 003-2021/TCE, concluye que los miembros del Jurado Nacional de Elecciones solo pueden ejercer la docencia universitaria a tiempo parcial. No se analizan con más detalle las características que debe reunir el ejercicio de la docencia.

En consecuencia, los miembros del Jurado Nacional de Elecciones solo pueden ser docentes a tiempo parcial de instituciones educativas públicas 
(universidad, instituto, escuela, academia, colegio, etc.), y, además, en instituciones educativas privadas (universidad, instituto, escuela, colegio, etc.) a tiempo completo (si este le alcanza) o parcial.

A continuación, se resumen las posibilidades que la legislación otorga para que los servidores públicos puedan desempeñarse como docentes:

a) Los servidores públicos en general pueden ejercer la docencia en cualquier universidad o institución educativa pública o privada, dentro o fuera del horario de trabajo; si lo hacen dentro del horario de trabajo, el número de horas que le dediquen no debe exceder las seis horas semanales y deben ser compensadas.

b) Los jueces y fiscales pueden ser docentes en universidades públicas o privadas a tiempo parcial, fuera del horario de despacho, con una carga lectiva máxima de ocho horas semanales como profesor ordinario en las categorías de profesor principal, asociado, auxiliar o profesor extraordinario o contratado, y siempre que el curso verse sobre materia jurídica.

c) Los congresistas pueden ejercer la docencia en cualquier universidad o institución educativa pública o privada fuera del horario de funcionamiento del Congreso.

d) Los miembros del Jurado Nacional de Elecciones pueden desempeñarse como docentes a tiempo parcial en cualquier universidad sea pública o privada.

e) Los miembros de la Junta Nacional de Justicia pueden ejercer la docencia en cualquier universidad pública o privada fuera del horario de trabajo.

Por último, coincidimos con el criterio establecido en el Acuerdo de Sala Plena 003-2021/TCE por el cual el Tribunal de Contrataciones reconoce que no tiene potestades para regular el ejercicio de la función docente, ya que esta excede los propósitos de la Ley de Contrataciones del Estado. Además, señala que la interpretación de los límites a la contratación de funcionarios como docentes de entidades públicas debe realizarse en función de las reglas y principios de la Constitución, así como de las normas específicas que regulan el ejercicio de la función pública en particular.

A pesar del análisis efectuado líneas arriba, aún queda la duda de si un funcionario público puede percibir doble remuneración del Estado por sus funciones docentes bajo los siguientes supuestos: a) tener a su cargo únicamente un curso, pero solo en una institución educativa pública; b) tener a su 
Cuadro2. Legislación sobre el ejercicio de la docencia por funcionarios

\begin{tabular}{|c|c|c|c|c|}
\hline Cargo & $\begin{array}{l}\text { Universidad } \\
\text { pública }\end{array}$ & $\begin{array}{l}\text { Universidad } \\
\text { privada }\end{array}$ & $\begin{array}{l}\text { Institución } \\
\text { educativa } \\
\text { pública }\end{array}$ & $\begin{array}{l}\text { Institución } \\
\text { educativa } \\
\text { privada }\end{array}$ \\
\hline $\begin{array}{l}\text { Servidores } \\
\text { públicos }\end{array}$ & Sí & Sí & Sí & Sí \\
\hline Jueces y fiscales & $\begin{array}{l}\text { Sí, fuera del } \\
\text { horario de trabajo }\end{array}$ & $\begin{array}{l}\text { Sí, fuera del } \\
\text { horario de trabajo }\end{array}$ & No & No \\
\hline Congresistas & $\begin{array}{l}\text { Sí, fuera del } \\
\text { horario de } \\
\text { funcionamiento } \\
\text { del Congreso }\end{array}$ & $\begin{array}{l}\text { Sí, fuera del } \\
\text { horario de } \\
\text { funcionamiento } \\
\text { del Congreso }\end{array}$ & $\begin{array}{l}\text { Sí, fuera del } \\
\text { horario de } \\
\text { funcionamiento } \\
\text { del Congreso }\end{array}$ & $\begin{array}{l}\text { Sí, fuera del } \\
\text { horario de } \\
\text { funcionamiento } \\
\text { del Congreso }\end{array}$ \\
\hline Miembros de JNJ & $\begin{array}{l}\text { Sí, fuera del } \\
\text { horario de trabajo }\end{array}$ & $\begin{array}{l}\text { Sí, fuera del } \\
\text { horario de trabajo }\end{array}$ & No & No \\
\hline Miembros de JNE & $\begin{array}{l}\text { Sí, a tiempo } \\
\text { parcial }\end{array}$ & Sí & $\begin{array}{l}\text { Sí, a tiempo } \\
\text { parcial }\end{array}$ & Sí \\
\hline
\end{tabular}

Elaboración propia.

cargo varios cursos en una misma institución educativa pública; o c) tener a su cargo el mismo curso en diversas instituciones educativas públicas.

\section{Conclusiones ${ }^{15}$}

La prohibición de doble percepción de ingresos en el Estado se remonta a 1717, cuando el rey Felipe V prohibió a los funcionarios percibir goces públicos duplicados bajo cualquier denominación. Esta disposición, en consecuencia, regía también para el Virreinato del Perú.

Las normas sobre servicio civil precisan que la docencia puede desarrollarse dentro o fuera del horario de trabajo. En el primer caso, debe ser compensada. Un servidor público, en general, se puede desempeñar como do-

15 Las afirmaciones que hago en este documento son a título personal en el marco de la libertad de cátedra establecida en el artículo 18 de la Constitución Política del Perú y no comprometen de modo alguno a las instituciones en las cuales laboro o presto servicios profesionales. 
cente en una universidad pública o privada, en una institución educativa de cualquier nivel educativo pública o privada o en una entidad del Estado que imparte formación profesional o laboral. El único requisito es que la docencia sea efectiva.

Los funcionarios públicos en general pueden impartir cátedra en una universidad pública como docentes ordinarios, extraordinarios —en cualquiera de sus categorías - o contratados, siempre que ejerzan la docencia a tiempo parcial. Pueden ser docentes investigadores, pero bajo la condición de que realicen docencia efectiva y solo se les retribuya esta. Igualmente, pueden desempeñarse como docentes en una o más universidades privadas. En este caso, la carga lectiva no debe exceder las seis horas semanales si las clases se desarrollan dentro del horario de trabajo de la entidad en la que laboran.

Los servidores públicos en general sí pueden ejercer la docencia universitaria fuera del horario de trabajo por la cantidad de horas que les sean factibles de dictar, tanto en universidades públicas como privadas, pero nunca en calidad de docentes a dedicación exclusiva y a tiempo completo.

Los jueces y fiscales pueden ser docentes universitarios a tiempo parcial, fuera del horario de despacho, con una carga lectiva máxima de ocho horas semanales como profesor ordinario en las categorías de profesor principal, asociado o auxiliar, o profesor extraordinario o contratado, siempre que el curso verse sobre alguna materia jurídica.

Los congresistas pueden ejercer la docencia en cualquier universidad o institución educativa pública o privada fuera del horario de funcionamiento del Congreso.

Los miembros del Jurado Nacional de Elecciones pueden desempeñarse como docentes a tiempo parcial en cualquier universidad pública y pueden ejercer, además, la docencia en universidades privadas.

Los miembros de la Junta Nacional de Justicia pueden trabajar en la docencia en cualquier universidad pública o privada fuera del horario de trabajo.

El Tribunal de Contrataciones no tiene potestades para regular el ejercicio de la función docente, ya que esta excede los propósitos de la Ley de Contrataciones del Estado. 


\section{Referencias}

Banco Central de Reserva del Perú. «Producto bruto interno por tipo de gasto (como porcentaje del PBI nominal), gráfico 95». Nota semanal 13. 8 de abril de 2021. https: / / www.bcrp.gob.pe/estadisticas/cuadros-de-la-nota-semanal.html (consultado el 12 de abril de 2021).

Boyer Carrera, Janery. El derecho de la función pública y el servicio civil: nociones fundamentales. Lima: Pontificia Universidad Católica del Perú, 2019). http:// repositorio.pucp.edu.pe/index/bitstream/handle/123456789/170359/El\%20 derecho $\% 20 \mathrm{de} \% 201 \mathrm{a} \% 20$ funcion $\% 20$ publica.pdf?sequence $=1 \&$ is Allowed $=\mathrm{y}$

Camargo Hernández, David Francisco. Funcionarios públicos: evolución y prospectiva. Eumed, s. f. https:/ /www.eumed.net/libros-gratis/2005/dfch-fun/index.htm

De Lessa Carvalho, F. Lins. «La función pública en el mundo: rasgos jurídicos, tendencias y retos de siete modelos comparados». AIS: Ars Iuris Salmanticensis 7, n. 1 (2019): 41-66. https://revistas.usal.es/index.php/ais/article/view/21889

Díez-Quijada, Ángel Martín. «La remuneración de los funcionarios». Revista de Administración Pública 39 (1962): 151-185. http: / / www.cepc.gob.es/publicaciones / revistas $/$ revistaselectronicas? $\mathrm{IDR}=1 \& \mathrm{IDN}=39 \& \mathrm{IDA}=22245$

Fortes Martín, Antonio. «La nueva fisonomía del derecho Administrativo en materia de contratación pública». Revista Digital de Derecho Administrativo 25 (2021): 11-53. https://revistas.uexternado.edu.co/index.php/Deradm/article/ view/6901/9469

González Iglesias, Miguel Ángel. En busca de la regeneración, renovación o mejora del comportamiento en la contratación pública: transparencia, lucha contra la corrupción, prohibiciones de contratar. La buena conducta empresarial. España: Universidad de Salamanca, 2020.

Martínez Alcubilla, Marcelo. Códigos antiguos de España. Colección completa de todos códigos de España, desde el Fuero Juzgo hasta la novísima recopilación. Madrid: Arco de Santa María, 1885.

Palomar Olmeda, Alberto. Derecho de la función pública: régimen jurídico de los funcionarios públicos, 11. ${ }^{a}$ ed. Madrid: Dykinson, 2016. 
Giovana Hurtado Magán

\section{Sobre la autora}

Abogada por la Universidad Femenina del Sagrado Corazón y magíster en Administración con mención en Dirección de Recursos Humanos. Especializada en Gestión de Programas de Educación a Distancia y TIC aplicadas a la educación superior, así como en Derecho laboral. Ha sido directora de la Escuela Nacional del Indecopi. Actualmente se desempeña como profesora de la Universidad ESAN y es subdirectora de Fortalecimiento de Capacidades en el Organismo de Evaluación y Fiscalización Ambiental (OEFA). 